\title{
Four Fourth Molars
}

\section{${ }^{1}$ Muralee M Choontharu, ${ }^{2}$ Rajendra Prasad, ${ }^{3}$ Kalpa M Pandya, ${ }^{4}$ Pradeep S}

\begin{abstract}
A supernumerary tooth is an additional entity to the normal series and can be seen in any of the quadrants of the jaw. Very often, they are associated with syndromes, such as Gardner syndrome and cleidocranial dysplasia. In the absence of any syndromes, occurrence of multiple supernumerary teeth is rare. Supernumerary molars can be in the form of paramolars or distomolars of which distomolars are relatively rare with a reported incidence of $2 \%$. We present a rare nonsyndromic case of four fourth molars in addition to an impacted maxillary canine. The treatment of supernumerary teeth depends on the current and possible effects on the adjacent teeth, the position of the tooth itself, and the likelihood of the development of pathologic conditions. Very often distomolars are treated as one treats the third molars. We also suggest a possible association between macrodontia and hyperdontia.
\end{abstract}

Keywords: Distomolars, Fourth molars, Supernumerary teeth.

How to cite this article: Choontharu MM, Prasad R, Pandya KM, Pradeep S. Four Fourth Molars. J Contemp Dent 2017; 7(3):166-168.

\section{Source of support: Nil}

Conflict of interest: None

\section{INTRODUCTION}

A supernumerary tooth is an additional entity to the normal series and can be seen in any of the quadrants of the jaw. ${ }^{1}$ Brook $^{2}$ in their study on 2000 schoolchildren found the prevalence of supernumerary tooth to be $2.1 \%$ of permanent dentition and $0.8 \%$ in primary dentition.

Increased incidence of supernumerary teeth may be present in cases of cleft lip and palate, Gardner syndrome, cleidocranial dysplasia, Ehlers-Danlos syndrome, Fabry Anderson syndrome, incontinentia pigmenti, trichorhinophalangeal syndrome, and chondroectodermal

\footnotetext{
${ }^{1,2}$ Professor, ${ }^{3}$ Fellow, ${ }^{4}$ Surgical Trainee

1,2Department of Oral and Maxillofacial Surgery, A.B. Shetty Memorial Institute of Dental Sciences, Mangaluru, Karnataka India

${ }^{3}$ Department of Head and Neck Surgical Oncology, Karnatak Cancer Therapy and Research Institute, Hubli, Karnataka, India

${ }^{4}$ Department of Surgical Oncology, Madras Medical College Chennai, Tamil Nadu, India

Corresponding Author: Kalpa M Pandya, Fellow, Department of Head and Neck Surgical Oncology, Karnatak Cancer Therapy and Research Institute, Hubli, Karnataka, India, Phone: +919632165530, e-mail: kalpa.pandya@gmail.com
}

dysplasia. ${ }^{3,4}$ In the absence of any syndromes, occurrence of multiple supernumerary teeth is rare. ${ }^{5}$

Supernumerary teeth are classified according to the morphology as conical, tuberculate, supplemental, and odontome; as per the position as mesiodens, distomolars, paramolars, or parapremolars. ${ }^{6}$

Of these, conical form is the most commonly found form in permanent dentition, presenting usually as a mesiodens. The least common is the supplemental variety, which appears like one of the normal series of teeth, often found at the end of the tooth series. ${ }^{7}$ Permanent maxillary lateral incisor is the most common supplemental tooth found.

Occurrence of supernumerary molars is rare. Cassetta et $\mathrm{al}^{7}$ reported an incidence of supernumerary molars as $0.18 \%$ of which majority were paramolars and the rest were distomolars. Kara et $\mathrm{al}^{8}$ reported an incidence of $0.33 \%$ for the same. Fourth molars are usually rudimentary in shape and impacted, ${ }^{9}$ generally identified through radiographs. ${ }^{10}$ Shahzad and Roth ${ }^{11}$ studied 409 patients and found that fourth molars have an incidence rate of $2 \%$ and are most commonly seen unilaterally in the maxilla. We describe a rare case of supplementary supernumerary bilateral, upper and lower fourth molars (distomolars) along with an impacted upper canine in a nonsyndromic patient.

\section{CASE REPORT}

A 19-year-old male patient came to the outpatient department of A.B. Shetty Memorial Institute of Dental Sciences with the chief complaint of pain in the lower right and left quadrant of the jaw since 5 days. On clinical examination, 38 and 48 appeared impacted with a portion of mesial cusp visible in both. A retained deciduous canine was present in the upper left quadrant. Orthopantomogram (OPG; Fig. 1) revealed impacted

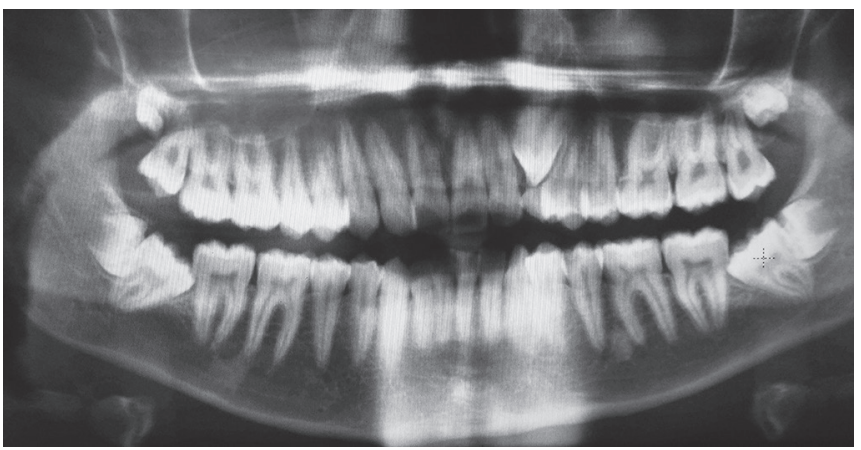

Fig. 1: The OPG showing four impacted fourth molars and an impacted left maxillary canine 


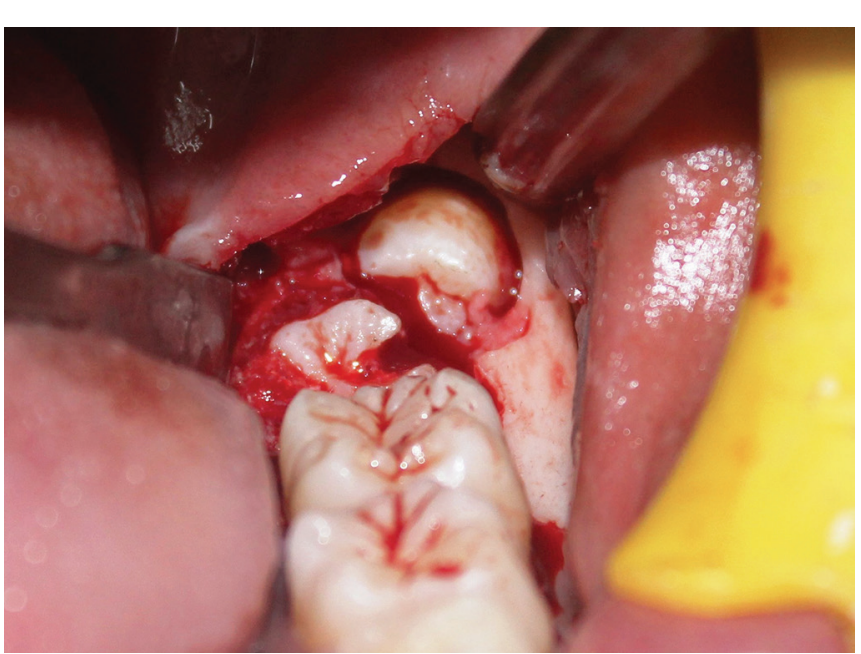

Fig. 2: Reflection of the mucoperiosteal flap reveals impacted third and fourth molars on the left side

lower third molars and distomolars bilaterally in the upper and lower arch. Also, an impacted upper left canine was present. It was decided to extract the lower third and the fourth molar bilaterally at an interval of 1 week. After the reflection of a mucoperiosteal flap, the bone over the third molar was removed, exposing the third and the fourth molars (Fig. 2). The crown of the fourth molar was distobuccal to and slightly overlapping the third molar buccally, making it necessary to first extract the fourth molar. This was followed by sectioning of the third molar along the long axis and elevation of the fragments. Morphologically, the fourth molar was of supplemental supernumerary type with only upper third of the root developed. A similar procedure was done on the left side after 1 week. Since the upper third molars were erupted and the upper fourth molars were asymptomatic, no surgical intervention was planned for the same. The unerupted canine was planned for orthodontically assisted extrusion. The patient was kept on a regular follow-up.

\section{DISCUSSION}

Paramolars are usually known to be in rudimentary form and occur buccal or palatal to the second, third, and rarely first molars. Distomolars as the name suggests occur distal to the third molars or may even occur distolingually. They are usually rudimentary and conical in shape. In the present case, both the mandibular fourth molars were supplemental in morphology and the upper fourth molars appeared to be conical in shape on OPG.

Grimanis et $\mathrm{al}^{4}$ in their survey of supernumerary molars observed that supernumerary molars occurred majority in maxilla $(79.7 \%)$ and only $23.9 \%$ occurred bilaterally. In the maxilla, they are more common anteriorly. They are also seen distal to third molars in the maxilla, mandibular premolar region, maxillary premolar region, maxillary canine region, and mandibular incisor region. Leco et $\mathrm{al}^{12}$ in their study on 2000 patients found that maxillary posterior region was the most commonly involved region ( $38 \%$ ) followed by maxillary anterior region(28.6\%). They reported the incidence of lower distomolars as only $4.8 \%$. Rajab and Hamdan ${ }^{3}$ in their survey have shown that 72 to $77 \%$ cases show multiple supernumerary teeth, 18 to $27 \%$ show bilateral supernumerary teeth, and only 1 to $5 \%$ show three supernumerary teeth. ${ }^{3}$ Nonsyndromic supernumerary teeth are uncommon entities and when present they often present singly and not in multiple numbers. ${ }^{5}$

Apart from causing a disturbance in the eruption and position of the adjacent teeth, supernumerary teeth increase the risk of pathological conditions, such as ameloblastoma, follicular cyst, and fistulae. ${ }^{13}$ This fact is a significant factor in deciding the management of supernumerary teeth. Leco et $\mathrm{al}^{12}$ in their previously mentioned study have reported complications, such as follicular cysts and displacement, failure of eruption, and lysis of the adjacent teeth which they termed as "mechanical accidents." Bereket et $\mathrm{al}^{14}$ in their study of 1100 supernumerary teeth have reported a complication rate of $38.36 \%$.

In cases where the related teeth have erupted satisfactorily, there is no associated pathology, no active orthodontic treatment has been planned, or removal may compromise the vitality of the adjacent tooth, observation has been the treatment of choice. ${ }^{13,15}$ Some authors suggest that fourth molars should be managed in a manner similar to third molars. ${ }^{9-11}$

In this case, we also observed that the patient had an overall large teeth size. This observation emphasizes the possibility made by Seehra et $\mathrm{al}^{16}$ that there may be a correlation between macrodontia and hyperdontia.

\section{CONCLUSION}

There is no rule of thumb regarding the management of supernumerary teeth, which depends on their position and associated conditions. When supernumerary teeth do not present any pathological, esthetic, or functional problems, they are best left alone with careful monitoring.

\section{REFERENCES}

1. Rajendran, A.; Sundaram, S. Shafer's textbook of oral pathology. 6th ed. Elsevier Health Sciences; 2014. p. 1001.

2. Brook AH. Dental anomalies of number, form and size: their prevalence in British schoolchildren. J Int Assoc Dent Child 1974 Dec;5(2):37-53.

3. Rajab LD, Hamdan MA. Supernumerary teeth: review of the literature and a survey of 152 cases. Int J Paediatr Dent 2002 Jul;12(4):244-254. 
4. Grimanis GA, Kyriakides AT, Spyropoulos ND. A survey on supernumerary molars. Quintessence Int 1991 Dec;22(12): 989-995.

5. Santos T de S, Silva ER, Faria AC, Mello Filho FV, Xavier SP. Multiple supernumerary teeth in a nonsyndromic 12-year-old female patient - a case report. Braz Dent J 2014 Feb;25(1):79-82.

6. Shah A, Gill DS, Tredwin C, Naini FB. Diagnosis and management of supernumerary teeth. Dent Update 2008 Oct;35(8):510-512, 514-516, 519-520.

7. Cassetta M, Altieri F, Giansanti M, Di-Giorgio R, Calasso S. Morphological and topographical characteristics of posterior supernumerary molar teeth: an epidemiological study on 25,186 subjects. Med Oral Patol Oral Cir Bucal 2014 Nov 1;19(6):e545-e549.

8. Kara MI, Aktan AM, Ay S, Bereket C, Şener İ, Bülbül M, Ezirganlı Ş, Polat HB. Characteristics of 351 supernumerary molar teeth in Turkish population. Med Oral Patol Oral Cir Bucal 2012 May;17(3):e395-e400.

9. Raley LL, Reichert E. Four impacted fourth molars. Oral Surg Oral Med Oral Pathol 1975 Oct;40(4):564-565.

10. Koo S, Salvador PS, Ciuffi Júnior J, de Silva Júnior AR. Bilateral maxillary fourth molars and a supernumerary tooth in maxillary canine region - a case report. SADJ 2002 Oct;57(10): 404-406.

11. Shahzad KM, Roth LE. Prevalence and management of fourth molars: a retrospective study and literature review. J Oral Maxillofac Surg 2012 Feb;70(2):272-275.

12. Leco Berrocal MI, Martín Morales JF, Martínez González JM. An observational study of the frequency of supernumerary teeth in a population of 2000 patients. Med Oral Patol Oral Cir Bucal 2007 Mar;12(2):E134-E138.

13. Parolia A, Kundabala M, Dahal M, Mohan M, Thomas MS. Management of supernumerary teeth. J Conserv Dent 2011 Jul;14(3):221-224.

14. Bereket C, Çakir-Özkan N, Şener I, Bulut E, BaŞtan AI. Analyses of 1100 supernumerary teeth in a nonsyndromic Turkish population: a retrospective multicenter study. Niger J Clin Pract 2015 Dec;18(6):731-738.

15. Garvey MT, Barry HJ, Blake M. Supernumerary teeth - an overview of classification, diagnosis and management. J Can Dent Assoc 1999 Dec;65(11):612-616.

16. Seehra J, Harrison M, Cobourne MT. Is there a relationship between increased tooth number and increased tooth size? A case report. Dent Update 2014 Aug;41(6):542-544. 